\title{
Walking Attainment in Very Low Birth Weight Infants in Japan
}

\author{
Yuu UchIO, PT, MSc ${ }^{1}$, Naoko ShIMA, $\mathrm{PT}^{1}$, Kaho NAKAMURA, $\mathrm{PT}^{1}$, \\ Osamu NiTTA, PT, $\mathrm{PhD}^{2}$ and Tetsuo IKAI, MD, $\mathrm{PhD}^{3}$ \\ ${ }^{1)}$ Department of Rehabilitation, Tokyo Women's Medical University, Japan \\ ${ }^{2}$ Department of Physical Therapy, Graduate School of Human Health Sciences, Tokyo Metropolitan University, Japan \\ ${ }^{3)}$ Department of Rehabilitation Medicine, Tokyo Women's Medical University, Japan
}

\begin{abstract}
Objective: To clarify the corrected age of walking attainment in very low birth weight infants by birth weight and gestational age, and determine perinatal factors affecting the delay in walking attainment. Method: This was a longitudinal study. We investigated walking attainment and perinatal factors in 145 very low birth weight infants without neurological abnormalities (mean birth weight $1019.3 \pm 299.7 \mathrm{~g}$, gestational age $29.0 \pm 2.9$ weeks). The study infants were stratified by birth weight (group A: $<1,000$ g, group B: $1,000 \mathrm{~g} \leq,<1,500 \mathrm{~g}$ ) and gestational age (group I: $<28$ weeks, group II: 28 weeks $\leq,<37$ weeks) and were compared using unpaired t-tests. Furthermore, we examined the perinatal factors that affect the delay in walking attainment using multiple regression analysis. Results: Of the walking attainment, infants in Group A were older than those in Group B (50th percentile, 15.8 vs. 14.7 months). Infants in Group I were older than those in Group II (50th percentile, 16.0 vs. 14.8 months). Using multiple regression analysis with walking attainment age as the dependent variable, the duration of mechanical ventilation was found to be significantly related. Conclusion: Very low birth weight infants with light weight and short gestational age have delayed walking attainment, and longer duration of mechanical ventilation increases the risk of delay.

Key words: Preterm infants, Very low birth weight, Motor milestone, Walking
\end{abstract}

(Phys Ther Res 00: 00-00, 0000)

Due to advances in neonatal care, the mortality rate of newborns has decreased in recent years ${ }^{1,2}$. On the other hand, the number of preterm births has been increasing ${ }^{3,4)}$. In particular, the number of very low birth weight (VLBW) infants, weighing less than $1,500 \mathrm{~g}$, has remarkably increased, and these infants have poor neurological outcomes $^{5,6)}$. Moreover, even if no neurological abnormality is observed, VLBW infants have delayed motor development relative to that in term infants ${ }^{7-9)}$; therefore, careful evaluation and observation are necessary.

In motor development, walking is the most significant motor milestone in terms of acquiring free locomotion and

Received: November 24, 2020

Accepted: March 3, 2021

Advance Publication by J-STAGE: May 10, 2021

Correspondence to: Yuu Uchio, Department of Rehabilitation, Tokyo Women's Medical University, Japan, 8-1 Kawatacho Shinjyuku-ku, Tokyo 162-8666, Japan

\# e-mail: yu-uch-247@u-ths.ac.jp

doi: 10.1298/ptr.E10087 social participation in a wider area. Furthermore, walking is the most perceptible index of motor development for the guardians of infants. Several studies have shown the timing of walking attainment in preterm infants as well as term infants ${ }^{10-13)}$. The factors affecting walking attainment in preterm infants are low birth weight ${ }^{14)}$ and the presence or absence of bronchopulmonary dysplasia (BPD) $)^{13}$.

Various studies have investigated the age of walking attainment in preterm infants; however, there are few reports on preterm infants in Japan. Therefore, it is important to report the walking attainment of Japanese VLBW infants. Furthermore, studies that have examined the influence of clinical data on the age of motor development are generally limited to relatively scarce medical conditions such as BPD ${ }^{13)}$.

The purpose of this study was to reveal the corrected age of walking attainment in VLBW infants by birth weight and gestational age, and to determine the perinatal factors that affect the delay in walking attainment. 


\section{Methods}

\section{Study design and population}

This longitudinal study included all VLBW infants born at Tokyo Women's Medical University Hospital from April 2010 to March 2017. The inclusion criteria were as follows: (i) birth weight of $<1500 \mathrm{~g}$; and (ii) gestational age of $<37$ weeks. The exclusion criteria were as follows: (i) diagnosed with chromosomal abnormalities, neurological disorders, or malformation syndromes; (ii) diagnosed with cerebral palsy; (iii) died in the hospital; and (iv) infants who were not followed up as an outpatient due to hospital transfer or relocation. The diagnosis of cerebral palsy was made by a doctor based on the definition of cerebral palsy by the age of 2 years ${ }^{15}$.

To reveal the age of walking attainment in VLBW infants by birth weight and gestational age, the infants were classified as follows: the study infants were divided into group A (birth weight $<1,000 \mathrm{~g}$ ) or group B $(1,000 \mathrm{~g} \leqq$ birth weight $<1,500 \mathrm{~g}$ ). The infants were also divided into group I (gestational age $<28$ weeks) or group II (28 weeks $\leq$ gestational age $<37$ weeks).

\section{Procedure}

Perinatal factors during neonatal intensive care unit (NICU) hospitalization and walking attainment ages were investigated retrospectively from medical records. Perinatal data were collected and included maternal age, multiple pregnancy, sex, gestational age, birth weight, head circumference at birth, small for gestational age (SGA), Apgar scores, cranial ultrasound findings (grading of intraventricular hemorrhage $(\mathrm{IVH})^{16)}$ and periventricular echo densities $\left.(\mathrm{PVE})^{17)}\right)$, presence or absence of periventricular leukomalacia (PVL), grading of retinopathy of prematurity $(\mathrm{ROP})^{18)}$, laser photocoagulation, duration of mechanical ventilation, presence or absence of respiratory distress syndrome (RDS), presence or absence of chronic lung disease (CLD) 28 which is defined as requiring oxygen 28 days after birth, home oxygen therapy, presence or absence of septicemia, presence or absence of symptomatic patent ductus arteriosus, patent ductus arteriosus ligation, presence or absence of late-onset circulatory collapse, and length of hospital stay.

In our hospital, VLBW infants are followed up by a physical therapist in a regular development outpatient department until they can walk. Guardians of infants were asked in a developmental outpatient department to monitor and record the date when the infant began walking for ten successive steps without support in a mother and child health handbook. After that, at the next outpatient development session, the physical therapist, who engaged with the infants from the NICU to the outpatient department, confirmed the gait status, and the walking attainment date was converted to the corrected age. The definition of walking attainment was based on the description of Denver II $^{19)}$ and was described to guardians as the day when the infant walked for 10 or more steps without support.

\section{Statistical methods}

We used unpaired t-tests to compare perinatal factors between the two groups, including gestational age, birth weight, head circumference at birth, duration of mechanical ventilation, and length of hospital stay. The chi-square test was used for multiple pregnancy, sex, SGA, PVL, laser photocoagulation, RDS, CLD 28, home oxygen therapy, septicemia, symptomatic patent ductus arteriosus, patent ductus arteriosus ligation, and late-onset circulatory collapse, while the Mann-Whitney U test was used to compare the Apgar scores, IVH, PVE, and ROP between the two groups. The Mann-Whitney U test was used to compare the timing of walking attainment age between the two groups by birth weight and gestational age. The distributions of the corrected age of walking attainment were estimated for each of the two groups using the Kaplan-Meier method and were compared using the log-rank test.

In addition, multiple regression analysis was used to reveal the perinatal factors that affect the delay of walking attainment in VLBW infants. First, Pearson's correlation coefficient or Spearman's rank correlation coefficient was used to determine the relationship between the walking attainment age and perinatal factors. In multiple regression analysis, the object variable was the walking attainment age, and the explanatory variables were the perinatal factors that significantly correlated with the walking attainment age according to the correlation analysis. The perinatal factors were entered simultaneously using the forced entry method.

All analyses were performed using IBM SPSS Statistics for Windows, version 23 (IBM Corp., Armonk, NY, USA). The significance level was set at $p<0.05$ for all analyses.

\section{Ethics statement}

This study was approved by the Tokyo Women's Medical University Ethics Committee (approval number: 5408). In addition, the disclosure of research information involved an opt-out system, and a veto right was guaranteed. For the management of personal information, we anonymized the data and ensured that individual patients could not be identified.

\section{Results}

\section{Study population}

There were 230 infants who weighed less than 1,500 g and had a gestational age of $<37$ weeks admitted during the study period from April 2010 to March 2017. Eleven infants were diagnosed with chromosomal abnormalities, 


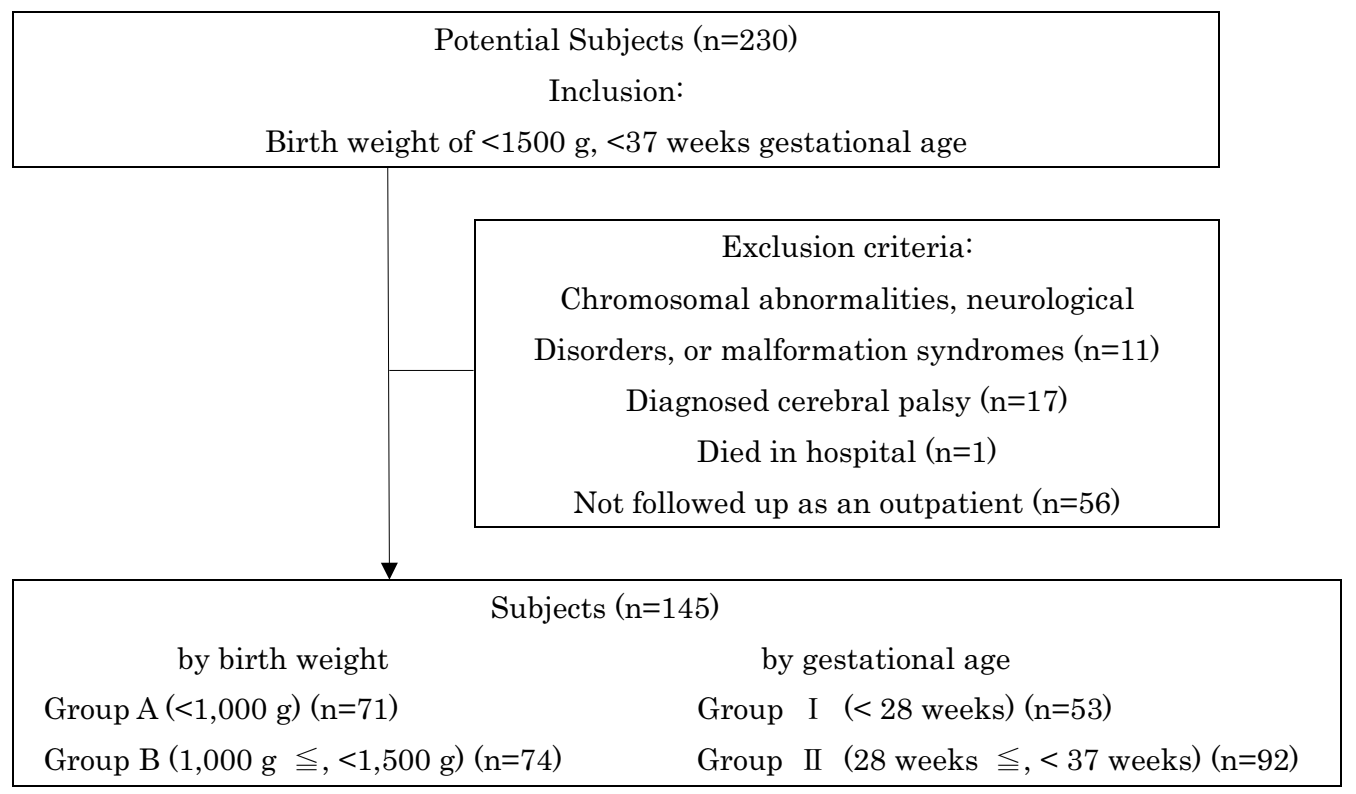

Fig. 1. Patient flow chart detailing the infants included in the study

neurological disorders, or malformation syndromes, 17 were diagnosed with cerebral palsy, 1 infant died in the hospital, and 56 infants were not followed-up as outpatients due to a hospital transfer or relocation. Thus, the analyzed population included 145 infants. The study infants were divided into group A $(n=71)$ or group $B(n=74)$ by birth weight. The infants were also divided into group I $(n=53)$ or group II ( $n=92)$ by gestational age (Fig. 1). The perinatal factors of each group are shown in Table 1.

\section{Corrected age of walking attainment in VLBW infants}

Table 2 shows the percentile values at the time of walking attainment by birth weight and gestational age. The 50th percentile value by birth weight was 15.8 months for group A and 14.7 months for group B, showing a significant difference between the two groups $(\mathrm{p}=0.003)$. The 50 th percentile by gestational age was 16.0 months in group I and 14.8 months in group II, showing a significant difference between the two groups $(\mathrm{p}<0.001)$.

Figure 2 shows Kaplan-Meier function plots of walking attainment age distribution by birth weights and by gestational age. Figure 2 shows that group A, comprising infants with a lower birth weight, showed later walking attainment than did group B $(p=0.002)$. Similarly, Group I, comprising infants with a shorter gestational age, showed later walking attainment than did group II $(\mathrm{p}<0.001)$.

Perinatal factors associated with delayed walking attainment age in $V L B W$ infants

As a result of the correlation analysis, the perinatal factors that were found to have a significant correlation with the walking attainment age were birth weight ( $r$ $=-0.364, \mathrm{p}<0.001)$, gestational age $(\mathrm{r}=-0.346, \mathrm{p}<0.001)$, head circumference at birth $(\mathrm{r}=-0.386, \mathrm{p}<0.001), 1$-minute
Apgar score $(\mathrm{r}=-0.244, \mathrm{p}=0.003), 5$-minute Apgar score $(\mathrm{r}$ $=-0.282, \mathrm{p}=0.001), \mathrm{IVH}(\mathrm{r}=0.293, \mathrm{p}<0.001), \mathrm{ROP}(\mathrm{R}=$ $0.271, \mathrm{p}=0.028)$, laser photocoagulation $(\mathrm{r}=0.241, \mathrm{p}=$ $0.004)$, duration of mechanical ventilation $(\mathrm{r}=0.422, \mathrm{p}<$ $0.001)$, CLD28 ( $r=0.189, \mathrm{p}=0.023)$, home oxygen therapy $(\mathrm{r}=0.194, \mathrm{p}=0.02)$ and sepsis $(\mathrm{r}=0.198, \mathrm{p}=0.017)$ (Table 3$)$.

Using multiple regression analysis with walking attainment age as the dependent variable, the duration of mechanical ventilation was found to be significantly related ( $p$ $=0.040)$ (Table 4). The variance inflation factor of all independent variables was less than 10 , so no evidence of predictor multicollinearity was found.

\section{Discussion}

In this study, we examined the walking attainment age in VLBW infants in relation to birth weight and gestational age, and clarified the perinatal factors that delay walking attainment. The 50th percentile value for walking attainment age in VLBW infants was 14.7 months for group B $(1,000$ $\mathrm{g} \leq$ birth weight $<1,500 \mathrm{~g})$ and 14.8 months for group II ( 28 weeks $\leq$ gestational age $<37$ weeks). On the other hand, the 50th percentile for walking attainment age was 15.8 months for group A (birth weight $<1,000 \mathrm{~g}$ ) and 16.0 months for group I (gestational age $<28$ weeks). Therefore, it was shown that walking attainment was more delayed with decreasing birth weight and gestational period. Our results support a previous study demonstrating that acquisition of gross motor skills in VLBW infants is more delayed as the birth weight and gestational period decrease $\mathrm{e}^{20,21)}$.

Marín Gabriel et al. ${ }^{20)}$ reported that the 50th percentile value of walking attainment age for VLBW infants was 1415 months at a birth weight less than $1000 \mathrm{~g}$, and 13 months at a birth weight between 1,000 and 1,500 g. Bu- 
Table 1. Perinatal factors of the subjects by birth weight and gestational age

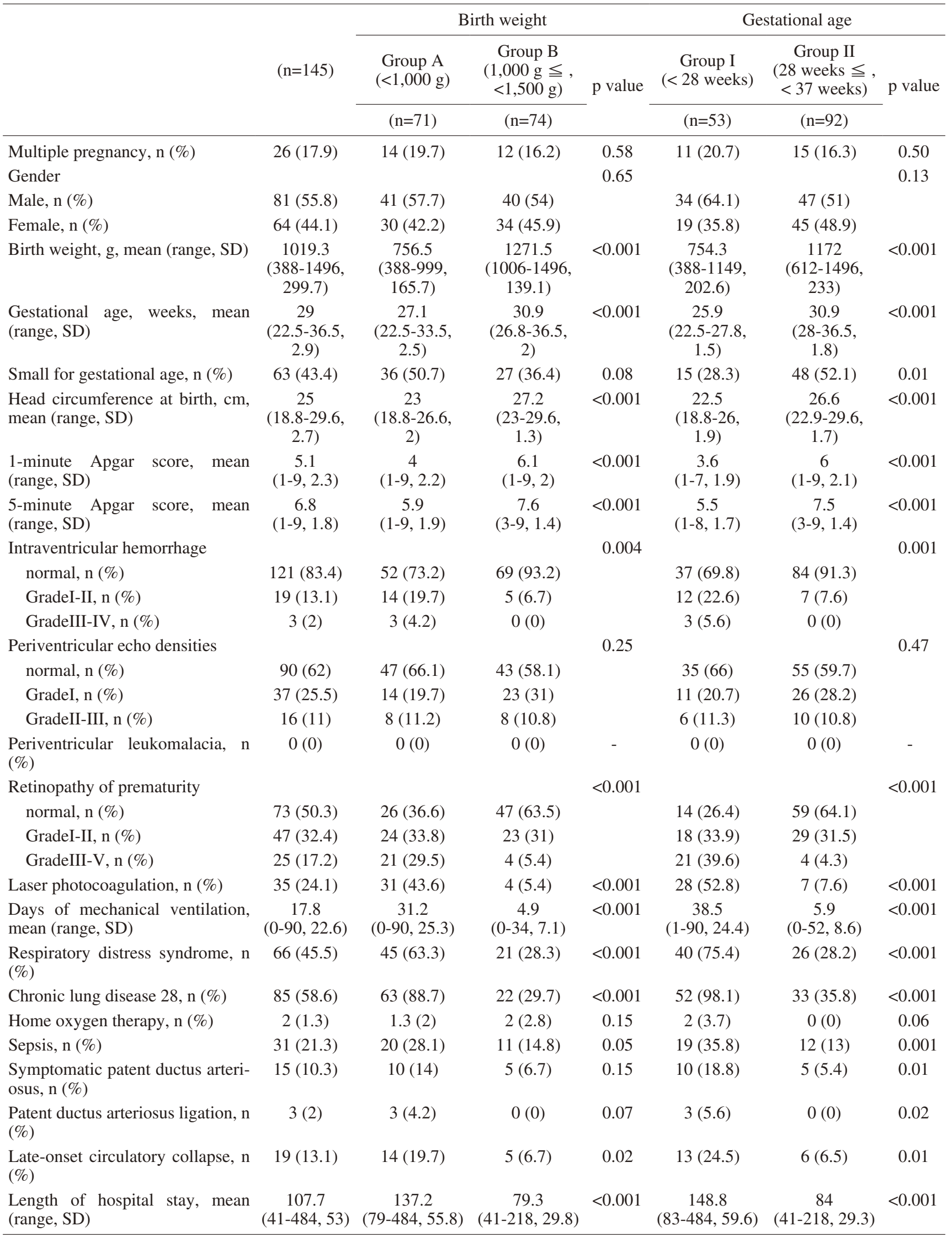

SD: standard deviation 
Table 2. Walking attainment time in very low birth weight infants by birth weight and gestational age (months)

\begin{tabular}{lccccc}
\hline & birth weight & $\mathrm{n}$ & 10th percentile & 50th percentile & 90th percentile \\
\hline Group A & $<1,000 \mathrm{~g}$ & 71 & 12.9 & 15.8 & 19.3 \\
Group B & $1,000 \mathrm{~g} \leqq,<1,500 \mathrm{~g}$ & 74 & 12.5 & 14.7 & 17.9 \\
\hline \multicolumn{5}{c}{} \\
\hline & gestational age & $\mathrm{n}$ & 10th percentile & 50th percentile & 90th percentile \\
\hline Group I & $<28$ weeks & 53 & 13.7 & 16 & 19.5 \\
Group II & 28 weeks $\leqq,<37$ weeks & 92 & 12.5 & 14.8 & 17.3 \\
\hline
\end{tabular}
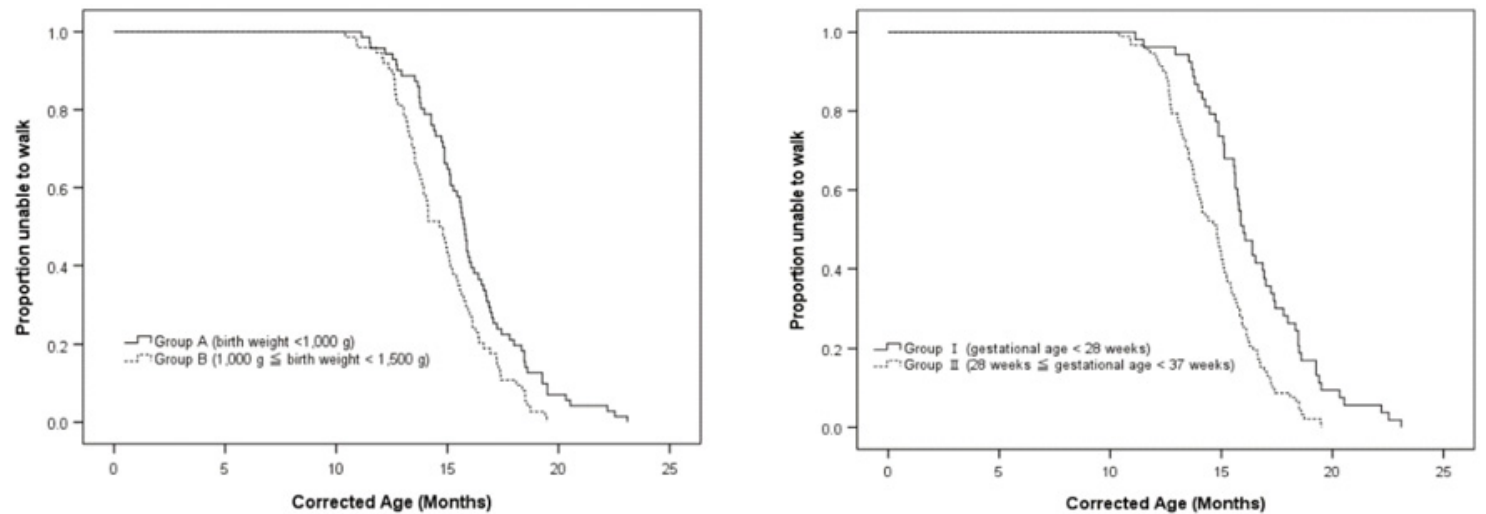

Fig. 2. Kaplan-Meier plots of corrected age of walking attainment for VLBW infants by birth weight and gestational age

Table 3. Correction analysis between walking attainment age and perinatal factors

\begin{tabular}{lcr}
\hline & $\begin{array}{c}\text { Correlation } \\
\text { coefficient } \\
(\mathrm{r})\end{array}$ & $\mathrm{p}$ value \\
\hline Multiple pregnancy & -0.145 & 0.083 \\
Gender & 0.077 & 0.356 \\
Birth weight & -0.364 & $<0.001$ \\
Gestational age & -0.346 & $<0.001$ \\
Small for gestational age & 0.037 & 0.659 \\
Head circumference at birth & -0.386 & $<0.001$ \\
1-minute Apgar score & -0.244 & 0.003 \\
5-minute Apgar score & -0.282 & 0.001 \\
Intraventricular hemorrhage & 0.293 & $<0.001$ \\
Periventricular echo densities & -0.088 & 0.292 \\
Periventricular leukomalacia & 0 & \\
Retinopathy of prematurity & 0.271 & 0.028 \\
Laser photocoagulation & 0.241 & 0.004 \\
Days of mechanical ventilation & 0.422 & $<0.001$ \\
Respiratory distress syndrome & 0.13 & 0.120 \\
Chronic lung disease 28 & 0.189 & 0.023 \\
Home oxygen therapy & 0.194 & 0.020 \\
Sepsis & 0.198 & 0.017 \\
Symptomatic patent ductus arteriosus & 0.108 & 0.195 \\
Patent ductus arteriosus ligation & 0.128 & 0.125 \\
Late-onset circulatory collapse & 0.144 & 0.085 \\
Length of hospital stay & -0.044 & 0.596 \\
\hline
\end{tabular}

cher et al. ${ }^{22)}$ also investigated walking attainment ages in term infants and in preterm infants with a median birth weight of 1,200 $\mathrm{g}$ and a median gestational age of 29.7 weeks. It was reported that more than $95 \%$ of preterm and term infants attained the ability to walk at a corrected age of 18 months. According to the results of this study, the walking attainment rates at the modified 18 months were as follows: group A, 80.3\%; group B, 90.5\%; group I, 73.6\%; group II, $92.2 \%$, and it was found that the walking attainment rate in this study was lower than that in previous stud$\operatorname{ies}^{12,22)}$. The reason for this is that Japanese infants have physiques different from those of infants in other Western countries, and the period of motor development may be delayed ${ }^{23,24)}$. The results of this study provide useful information to the caregivers and medical staff of Japan's VLBW infants regarding the unique walking attainment age based on birth weight and gestational age in Japan.

In multiple regression analysis, the duration of mechanical ventilation was adopted as a factor affecting walking attainment. The reason that walking attainment is delayed in children requiring long-term artificial respiration management may be that they are forced to take long-term rest for preventive purposes such as unplanned extubation. Prolonged ventilator management may delay early gross motor development ${ }^{25)}$. Since walking attainment age is related to the acquisition of initial gross motor skills such as the ability to support the head and stand upright, it is con- 
Table 4. Multiple regression analysis with walking attainment age as the dependent variable

\begin{tabular}{lcccccc}
\hline & $\begin{array}{c}\text { Unstandardized } \\
\text { coefficients }\end{array}$ & $\begin{array}{c}\text { 95\% Confidence } \\
\text { interval for B }\end{array}$ & $\begin{array}{c}\text { Standardized } \\
\text { coefficients }\end{array}$ & p value & VIF \\
\cline { 2 - 4 } & $\mathrm{B}$ & & $\beta$ & & \\
\hline Birth weight & -0.008 & $(-0.101 \sim 0.085)$ & -0.035 & 0.864 & 6.171 \\
Gestational age & 1.078 & $(-0.117 \sim 2.273)$ & 0.312 & 0.077 & 4.647 \\
Head circumference at birth & -6.796 & $(-18.55 \sim 4.959)$ & -0.267 & 0.254 & 8.28 \\
1-minute Apgar score & -0.422 & $(-10.124 \sim 9.279)$ & -0.014 & 0.931 & 3.997 \\
5-minute Apgar score & 4.5 & $(-10.425 \sim 19.426)$ & 0.113 & 0.551 & 5.496 \\
Intraventricular hemorrhage & 14.059 & $(-3.689 \sim 31.806)$ & 0.141 & 0.119 & 1.227 \\
Retinopathy of prematurity & 8.612 & $(-3.724 \sim 20.948)$ & 0.15 & 0.169 & 1.794 \\
Laser photocoagulation & -1.638 & $(-38.041 \sim 34.765)$ & -0.01 & 0.929 & 2.005 \\
Days of mechanical ventilation & 1.004 & $(0.045 \sim 1.964)$ & 0.325 & 0.04 & 3.734 \\
Chronic lung disease 28 & -1.909 & $(-33.87 \sim 30.052)$ & -0.013 & 0.906 & 1.903 \\
Home oxygen therapy & 73.2 & $(-64.385 \sim 210.785)$ & 0.094 & 0.294 & 1.225 \\
Sepsis & 30.919 & $(-1.108 \sim 62.946)$ & 0.176 & 0.058 & 1.293 \\
\hline
\end{tabular}

Full model $\mathrm{R}=0.53, \mathrm{R}^{2}=0.28$, adjusted $\mathrm{R}^{2}=0.20$

VIF: variance inflation factor

sidered that delays in initial gross motor development contribute to delayed walking. Low birth weight infants with mechanical ventilation had significantly delayed gross motor development at 8 to 12 months compared to that in infants without mechanical ventilation ${ }^{26)}$. In addition, it has been reported that children who needed long-term mechanical ventilation show decreased adolescent motor function scores and low psychomotor development indices, even in the absence of neurological abnormalities ${ }^{27,28)}$. Since artificial respiration management affects mental and motor development after walking attainment, it is necessary to carefully conduct long-term follow up of these children. BPD is also defined as requiring oxygen for $>30$ days or after 35 weeks postmenstrual age ${ }^{13)}$. In our hospital, CLD 28, which required oxygen administration even beyond 28 days after birth, is recorded in the medical record as a factor of immature lungs. Therefore, CLD 28 was used instead of BPD in this study. The reason why CLD 28 was not adopted as a risk factor for delayed walking attainment is clinically considered to be that ventilator management, which requires more rest than oxygen administration, is involved in motor development.

Our study has some limitations. First, the study excluded infants who had a diagnosis of cerebral palsy by a corrected age of 2 years. Thus, infants included may have been diagnosed with cerebral palsy after 2 years, or with psychomotor retardation. Second, in the multiple regression analysis, the coefficient of determination $\left(\mathrm{R}^{2}=0.28\right)$, which is the contribution percentage of the independent variable, was low. It has been reported that locomotor activity in infancy is related to the timing of walking attainment ${ }^{29}$. In the future, in order to predict children with delayed walking attainment, it will be necessary to consider the evaluation of spontaneous movement in addition to perinatal factors.
Third, the sample size was relatively small. A larger study population followed-up at multiple centers is needed.

\section{Conclusion}

The results of this study showed that VLBW infants with light weight and short gestational age have delayed walking attainment, and longer duration of mechanical ventilation increases the risk of delay. Therefore, intervention with developmental support from an early stage may lead to improvement of gross motor skills in such cases.

Acknowledgments: This research received no specific grant from any funding agencies in the public, commercial, or not-for-profit sectors. We would like to thank Dr. Masaki Wada and Dr. Satsuki Totsu for their useful comments on the manuscripts.

Conflict of Interest: There are no conflicts of interest to declare.

\section{References}

1) UNICEF: Levels \& Trends in Child Mortality: Report 2019Estimates developed by the UN Inter-agency Group for Child Mortality Estimation. Unicef/WHO/WBG/UN, 2019, pp. 1-32.

2) Rüegger C, Hegglin M, et al.: Population based trends in mortality, morbidity and treatment for very preterm- and very low birth weight infants over 12 years. BMC Pediatr. 2012; 12: 17.

3) Chawanpaiboon S, Vogel JP, et al.: Global, regional, and national estimates of levels of preterm birth in 2014: a systematic review and modelling analysis. Lancet Glob Heal. 2019; 7: e3746.

4) Blencowe H, Cousens S, et al.: National, regional, and worldwide estimates of preterm birth rates in the year 2010 with time 
trends since 1990 for selected countries: A systematic analysis and implications. Lancet. 2012; 379: 2162-2172.

5) Kusuda $S$, Fujimura M, et al.: Trends in morbidity and mortality among very-low-birth-weight infants from 2003 to 2008 in Japan. Pediatr Res. 2012; 72: 531-538.

6) Saigal S and Doyle LW: An overview of mortality and sequelae of preterm birth from infancy to adulthood. Lancet. 2008; 371 : 261-269.

7) de Kieviet JF, Piek JP, et al.: Motor development in very preterm and very low-birth-weight children from birth to adolescence. JAMA. 2009; 302: 2235-2242.

8) Pietz J, Peter J, et al.: Physical growth and neurodevelopmental outcome of nonhandicapped low-risk children born preterm. Early Hum Dev. 2004; 79: 131-143.

9) Husby IM, Skranes J, et al: : Motor skills at 23years of age in young adults born preterm with very low birth weight. Early Hum Dev. 2013; 89: 747-754.

10) De Onis M: WHO Motor Development Study: Windows of achievement for six gross motor development milestones. Acta Paediatr. 2006; 95: 86-95.

11) Kimura-Ohba S, Sawada A, et al.: Variations in early gross motor milestones and in the age of walking in Japanese children. Pediatr Int. 2011; 53: 950-955.

12) Jeng SF, Lau TW, et al.: Development of walking in preterm and term infants: Age of onset, qualitative features and sensitivity to resonance. Gait Posture. 2008; 27: 340-346.

13) Campbell SK and Hedeker D: Validity of the test of infant motor performance for discriminating among infants with varying risk for poor motor outcome. J Pediatr. 2001; 139: 546-551.

14) Hediger ML, Overpeck MD, et al.: Birthweight and gestational age effects on motor and social development. Paediatr Perinat Epidemiol. 2002; 16: 33-46.

15) Carr LJ, Reddy SK, et al.: Definition and classification of cerebral palsy. Dev Med Child Neurol. 2005; 47: 508-510.

16) LA Burstein J, Burstein R, et al.: Incidence and evolution of subependymal and intraventricular hemorrhage: a study of infants with birthweights less than 1500 gm. J Pediatr. 1978; 92: 529-534.

17) Pidcock FS, Graziani LJ, et al.: Neurosonographic features of periventricular echo densities associated with cerebral palsy in preterm infants. J Pediatr. 1990; 116: 417-422.
18) Committee for the classification of retinopathy of prematurity: An international classification of retinopathy of prematurity. Arch Ophthalmol. 1984; 102: 1130-1134.

19) Frankenburg WK, Dodds J, et al.: The DENVER II training manual. In: Frankenburg WK (ed): 4. Directions for Administration of Specific Items, Denver Developmental Materials, Inc., Colorado, 1992, pp. 17-33.

20) Marín Gabriel MA, Pallás Alonso CR, et al: : Age of sitting unsupported and independent walking in very low birth weight preterm infants with normal motor development at 2 years. Acta Paediatr Int J Paediatr. 2009; 98: 1815-1821.

21) Restiffe AP and Gherpelli JLD: Differences in walking attainment ages between low-risk preterm and healthy full-term infants. Arq Neuropsiquiatr. 2012; 70: 593-598.

22) Bucher H, Killer C, et al.: Growth, developmental milestones and health problems in the first 2 years in very preterm infants compared with term infants: A population based study. Eur J Pediatr. 2002; 161: 151-156.

23) Ueda R: Child development in Okinawa compared with Tokyo and Denver, and the implications for developmental screening. Dev Med Child Neurol. 1978; 20: 657-663.

24) Ueda R: Standardization of the Denver developmental screening test on tokyo children. Dev Med Child Neurol. 1978; 20: 647656.

25) Jeng SF, Yau KI, et al.: Prognostic factors for walking attainment in very low-birthweight preterm infants. Early Hum Dev. 2000; 59: 159-173.

26) Nazi S and Aliabadi F: Comparison of motor development of low birth weight (LBW) infants with and without using mechanical ventilation and normal birth weight infants. Med J Islam Repub Iran. 2015; 29: 1-7.

27) Walsh MC, Morris BH, et al.: Extremely low birthweight neonates with protracted ventilation: mortality and 18-month neurodevelopmental outcomes. J Pediatr. 2005; 146: 798-804.

28) Whitaker AH, Feldman JF, et al.: Motor and cognitive outcomes in nondisabled low-birth-weight adolescents: early determinants. Arch Pediatr Adolesc Med. 2006; 160: 1040-1046.

29) Jeng SF, Chen LC, et al: : Relationship between spontaneous kicking and age of walking attainment in preterm infants with very low birth weight and full-term infants. Phys Ther. 2004; 84: 159-172. 